\title{
Correlation of dyspeptic symptoms and endoscopic findings in diabetic
} patient

\author{
Ramazan Ilyas Oner ${ }^{*}$, Melih Karincaoglu²
}

\begin{abstract}
Objective: We aimed to demonstrate the relationship between the endoscopically increased mucosal damage and the frequency of dyspeptic symptoms in patients with diabetes.

Material and Methods: The 42 diabetic patients with dyspeptic complain and 40 healthy dyspeptic people were involved in this study and evaluated with video endoscopes.

Results: Diabetic patients when compared with the control group according to the endoscopic evaluation and Glasgow Dyspepsia Symptom Scoring System no significant difference had been detected. The symptoms of the diabetic group and the control group were familiar and there was no significant difference between the frequencies of the symptoms in both groups. In dyspeptic diabetic patients a weak correlation between BMI and endoscopically detected hiatal hernia was reported. However there was no relation between BMI and the other gastrointestinal symptoms. Also there was no difference between the patients with neuropathy and without neuropathy in terms of endoscopic findings and gastrointestinal symptoms.
\end{abstract}

Conclusion: Endoscopic findings of diabetic patient and non-diabetic control group were compared statistically. Although gastric ulcus was significantly higher in diabetic group, there was no significant difference between two groups in terms of other endoscopic findings. Hovewer, gastric ulcus frequency in diabetic group is higher, there were no significant difference in terms of gastrointestinal symptoms, diabetic complications and glisemic control in patients with other endoscopic lesions when compared with the patients with gastric ulcus. Hiatal hernia frequency in diabetic patients was higher due to control group. In shed light on our findings, diabetic patients must be evaluated for the esophageal reflux symptoms.

Keywords: Diabetes mellitus, Dyspepsia, Endoscopy

\section{Introduction}

Diabetes mellitus (DM) is a chronic disease characterized by anomalies in carbohydrate, protein and lipid metabolism. Chronic and continuous exposure to these anomalies cause microvascular complications (retinopathy, neuropathy, nephropathy), macrovascular complications (myocardial infarction, stroke, peripheral artery disease) (1), gastrointestinal (gastroparesis, diarrhea), genitourinary (uropathy/sexual dysfunction) and dermatological complications.

Chronic hyperglycemia leads to complications in DM by increasing the activity of sorbitol pathway of metabolism, causing the formation of advanced glycosylation end products (AGE) by means of the non-enzymatic glycosylation of cellular proteins of increased intracellular glucose and increasing the formation of diacylglycerol by activating certain isoforms of protein kinase C (PKC) (1).
'Dyspepsia' expresses an exact definition; however, it is generally defined as the indicator of upper gastrointestinal symptoms and most of the patients with dyspepsia have an organic or functional disorder of upper gastrointestinal system. The symptoms of dyspepsia involve upper abdominal pain/discomfort, anorexia, bloating, early satiety, nausea and/or vomiting, and it affects up to 7-40\% of the general population.

Upper gastrointestinal endoscopy is the most convenient initial test to evaluate patients with dyspepsia (2). The factors leading to gastrointestinal symptoms in DM patients are autonomic neuropathy, poor glycemic control, psychiatric disorders and metabolic disorders secondary to diabetes. A significant association has been detected between gastric emptying and the severity of autonomic neuropathy. 
Parasympathetic dysfunction developing secondary to chronic hyperglycemia affected emptying function, and as well as, antroduodenal motor activity, gastroesophageal reflux activity and gastric secretion. In 1958, the reducing effect of diabetes associated with autonomic neuropathy on the gastric emptying was defined as 'Gastroparesis diabeticorum' and it has been encountered in almost $25 \%$ of the DM patients (3).

The incidence of diarrhea or constipation, abdominal pain or discomfort, heartburn, dysphagia, nausea, vomiting and fecal incontinence is higher in DM patients, and basal and stimulated gastric acid secretion has been reported to be normal or decreased (4). The secondary symptoms are gastroparesis, and alterations in motility of small and large intestine. The lesions, such as gastric ulcer, duodenal ulcer, gastritis and esophagitis, should be evaluated by GIS endoscopy before establishing a correlation between gastrointestinal symptoms and gastroparesis in DM patients (5).

In the present study, it was aimed to demonstrate the relation between the prevalence of dyspeptic symptoms and endoscopically increased mucosal damage in patients having DM with dyspeptic symptoms.

\section{Material and method}

The present prospective clinical studies were conducted on 42 DM patients, aged 35 to 76 years, who were admitted to Gastroenterology Outpatient Clinic of Turgut Ozal Medical Center, Inonu University Faculty of Medicine, between April 2004 and September 2005, with complaint of dyspepsia, and 40 control patients, aged 18 to 77 years, without a comorbid disease. The approval of the local ethics committee was obtained from the Inonu University, Faculty of Medicine.

Upper GIS endoscopy was performed with Olympus GF-XQ 200 (Olympus, Japan) in all patients by the gastroenterology specialists in our department. The spectrophotometric analysis of complete blood count and the nephelometric analysis of other biochemical parameters were performed with LH750-ANA device (Beckman Coulter, USA) analyzer and Olympus AU 600 analyzer (Olympus, USA) respectively.

The dyspeptic complaints of patients, involving pain, bloating, indigestion, gastric fullness, early satiety, excessive belching and burping, nausea, vomiting and heartburn were examined, and evaluated by using Glasgow Dyspepsia Severity Scale (GDSS) (Table 1) (6).

Patients who having any alarm symptoms such as weight loss, anemia, dysphagia, epigastric mass, persistent vomiting, patients having a concomitant severe systemic disease, pregnant or lactating women having the signs of being pregnant, patients having perception and adjustment disorder (mental disease or defect), and those having alcohol addiction or drug abuse were excluded from the study. one of 82 patients was excluded from the study due to intolerance to esophagogastroduodenoscopy.

Statistical analysis was performed by using SPSS 10.0 Windows package program. All data were calculated as mean \pm standard deviation (SD). According to the findings of esophagogastroduodenoscopy, study and control groups were compared by using Pearson ChiSquare Test. A $p$-value of $<0.05$ was accepted as statistically significant.

\section{Results}

Forty-two DM patients with complaints of dyspepsia and 40 patients with dyspepsia having no comorbid diseases were included in this study. The mean age of study group, including 20 males $(47.6 \%)$ and 22 females $(52.4 \%)$, was $50.8 \pm 9.2$ years; the control group consisted of 17 males $(42.5 \%)$ and 23 females $(57.5 \%)$.

Twenty-three DM patients had a comorbid disease, such as hypertension, cardiac disease, osteoporosis $(54.8 \%) ; 19$ patients had no systemic disease $(45.2 \%)$.

The drug list and habits of the patients in the study and control groups were presented in table 2 and table 3 .

According to the diabetic complications, 6 patients had microalbuminuria $(14.3 \%), 12$ patients had retinopathy $(28.6 \%)$ and 27 patients had polyneuropathy $(64.3 \%)$.

There was no statistically significant difference between the GDSS of diabetic and non-diabetic patients $($ GDSS $=7.40 \pm 3.54$ and GDSS $=6.87 \pm$ 3.29 , respectively) $(\mathrm{p}=0.487)$.

Esophagogastroduodenoscopic examination of diabetic patients revealed that 40 had antral gastritis (97.6\%), the 13 had pangastritis $(31.7 \%)$, the 4 had gastric ulcer $(9.8 \%)$, the 4 had duodenal ulcer $(9.8 \%)$, the 17 had bulbitis $(41.5 \%)$, the 10 had cardiac insufficiency $(24.4 \%)$, the 2 had hiatal hernia (14.6\%), and two had esophagitis (4.9\%).

In the patients of control group (non-DM), the 35 had antral gastritis $(87.5 \%)$, the 8 had pangastritis (20\%), the 4 had duodenal ulcer $(10 \%)$, the 12 had bulbitis $(30 \%)$, the 4 had cardiac insufficiency $(10 \%)$, the 5 had hiatal hernia $(12.5 \%)$ and the 4 had esophagitis (10\%) according to the esophagogastroduodenoscopic examination, and none of them had gastric ulcer. 
The most common lesion was antral gastritis in both groups $(97.6 \%$ in study group; $87.5 \%$ in control group). While esophagitis was detected in the diabetic patients (4.9\%), gastric ulcer was not observed in none of the patients in non-diabetic dyspepsia group.
According to the findings of esophagogastroduodenoscopy, study and control groups were compared by using Pearson Chi-Square. There was no significant difference between the groups due to endoscopic findings, except the high frequency of gastric ulcer $(\mathrm{p}=0.043)$ (Table 4).

Table 1: Glasgow Dyspepsia Symptom Scoring System

\section{1- Frequency of dyspeptic symptoms}

How often have you complained of a dyspeptic complaint in the last six months?

Never happened

Score

Only 1 or 2 days

0

One day a month

One day per week

Approximately every two days

\section{2- Effect on normal activities}

Do your dyspeptic complaints affect your normal activities such as sleeping,

eating or social activities?

$\begin{array}{ll}\text { No, it does not affect } & 0 \\ \text { Sometimes it is affecting } & 1 \\ \text { Always affected } & 2\end{array}$

\section{3-Time off work}

How many days did you go to work because of your dispeptic complaints in the last 6 months

Therefore it was not the day I did not go to work 0

I did not go 1-7 days

I did not go over 7 days

\section{4- Consultation with medical profession}

How often did you go to a doctor for the cause of your dyspeptic complaints in the last 6 months?

\begin{tabular}{|lc|}
\hline I never went & 0 \\
\hline Once & 1 \\
\hline Two or more & 2 \\
\hline
\end{tabular}

\section{5- Doctor visits to home}

Have you called your doctor for your dyspeptic complaints in the last six months?

I never called

Once

\section{6- Tests for dyspepsia}

Two or more $\quad 2$

How many times have you tested for the cause of your dyspeptic complaints in the last 6 months?

$\begin{array}{ll}\text { I never did it } & 0 \\ \text { Once } & 1 \\ \text { Two or more } & 2\end{array}$

\section{7- Treatment for dyspepsia}

a- How often did you use medication without going to the doctor with your own decision?

I've never used

Less than once a week

More than once a week

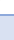

2

\begin{tabular}{|cc|}
\hline I've never used & 0 \\
\hline Less than once a week & 1 \\
\hline More than once a week & 2 \\
\hline b- How long have you used prescription medication for your dyspeptic complaints \\
\hline in the last six months & 0 \\
\hline One or less per month & 1 \\
\hline $1-3$ months & 2 \\
\hline 3 months more
\end{tabular}


Table 2: Distribution of drugs and habits of diabetic patients

\begin{tabular}{lcccc} 
& \multicolumn{2}{c}{ User } & \multicolumn{2}{c}{ Not Using } \\
& $\mathbf{n}$ & $\mathbf{\%}$ & $\mathbf{n}$ & $\mathbf{\%}$ \\
Cigarette & 10 & 23,8 & 32 & 76,2 \\
Alcohol & 2 & 4,8 & 40 & 75,2 \\
NSAID* & 27 & 64,3 & 25 & 35,7 \\
Aspirin & 19 & 45,2 & 23 & 54,8 \\
Steroid & 0 & 0 & 42 & 100 \\
OAD** & 31 & 73,8 & 11 & 26,2 \\
Insulin & 12 & 28,6 & 30 & 71,4 \\
\hline
\end{tabular}

Table 3: Distribution of drugs and habits of nondiabetic patients

\begin{tabular}{lcccc} 
& \multicolumn{2}{c}{ User } & \multicolumn{2}{c}{ Not Using } \\
& $\mathbf{n}$ & $\mathbf{\%}$ & $\mathbf{n}$ & $\%$ \\
Cigarette & 11 & 27,5 & 29 & $\mathbf{7 2 , 5}$ \\
Alcohol & 5 & 12,5 & 35 & $\mathbf{8 7 , 5}$ \\
NSAİD* & 20 & 50 & 20 & $\mathbf{5 0}$ \\
Aspirin & 1 & 2,5 & 39 & $\mathbf{9 7 , 5}$ \\
Steroid & $\mathbf{0}$ & $\mathbf{0}$ & $\mathbf{4 0}$ & $\mathbf{1 0 0}$ \\
\hline
\end{tabular}

* Nonsteroidal anti-inflammatory drugs

*Nonsteroidal anti-inflammatory drugs

** Oral antidiabetic drugs

Table 4: Comparison of endoscopic findings of patients according to Pearson Chi-Square test

\begin{tabular}{lccccc} 
OGD* Findings & \multicolumn{2}{c}{ Diabetic Patients } & \multicolumn{2}{c}{ Control Group } & P value \\
& $\mathrm{n}$ & $\%$ & $\mathrm{n}$ & $\%$ & \\
Antral Gastritis & 40 & 97,6 & 35 & 87,5 & 0,084 \\
Pangastritis & 13 & 31,7 & 8 & 20 & 0,229 \\
Gastric Ulcer & 4 & 9,8 & 0 & 0 & $\mathbf{0 , 0 4 3}$ \\
Duodenal Ulcer & 4 & 9,8 & 4 & 10 & 0,971 \\
Bulbitis & 17 & 41,5 & 12 & 30 & 0,282 \\
Cardiac Insufficiency & 10 & 24,4 & 4 & 10 & 0,087 \\
Hiatal Hernia & 6 & 14,6 & 5 & 12,5 & 0,779 \\
Esophagitis & 2 & 4,9 & 4 & 10 & 0,379 \\
\hline
\end{tabular}

*Esophagogastroduodenoscopy

\section{Discussion}

Gastric motor and sensory disorders associated with irreversible autonomic neuropathy, poor glycemic control, demographic and physiological characteristics are the indicators of gastric emptying and upper GIS symptoms in diabetic patients. Autonomic nerve functions and glycemic control have primary significant effects.

The relationship between GIS symptoms and glycemic control in diabetic patients has been shown in various studies. The prevalence of GIS symptoms was found to be higher in patients with poor glycemic control (7). Koch et al. reported in their study that glycemic control did not show any correlation with worsening gastrointestinal symptoms (8). Although, the diabetic patients had poor glycemic control in our study $(\mathrm{HbA1C}=9.9 \pm 2.8)$, Statistically significant difference between the groups in terms of GDSS and esophagogastroduodenoscopic findings were not found. The acute blood glucose alterations have major effects on the gastric emptying and upper GIS senses.
In a recent cohort study by Bharucha et al., a correlation was reported between $\mathrm{HbA1C}$ and delayed gastric emptying (9)

Schvarcz et al. showed that the prevalence of gastrointestinal symptoms was significantly higher in diabetic women than diabetic men (10). In the present study, statistically significant difference between the genders in terms of symptom scoring and endoscopic findings were not found.

Gastric emptying might be affected by body weight in healthy individuals, and may associate with eating habits, as well. Obesity might cause rapid or slow gastric emptying in healthy groups; however, gastric emptying was delayed in functional dyspepsia patients with low weight. In a meta-analysis published in 2012, significant associations were found between BMI and gastrointestinal symptoms, including reflux, diarrhea, upper abdominal pain, vomiting and heartburn, there was no relationship between BMI and the symptoms, including common abdominal pain, bloating, constipation, lower abdominal pain and nausea (11). 
In the present study, a weak correlation was detected between BMI and hiatal hernia in the endoscopic assessment of the diabetic patients with dyspepsia $(\mathrm{p}=0.02$ and $\mathrm{r}=0.35$ ). However, there was no significant association between BMI and other endoscopic findings and frequency of GI symptoms.

Another factor causing abnormal gastric motor function is the receptive relaxation of the fundus and reduced antral motor activity. The postprandial antral motor activity (motility index) is decreased in diabetic patients (12). Despite of a slow tonus rhythm of fundus during starvation, fundic tonus is higher in diabetic patients in comparison to the healthy individuals. Prolonged phase- 2 was observed in diabetic patients (12), and phase-3 was almost disappeared in 6-7 juvenile patients with Type-1 diabetic gastroparesis (13). In a study performed with 45 patients with cardiovascular autonomic neuropathy, semi-solid nutrients were given to the patients, the ratio of proximal/distal stomach was significantly decreased in 32 patients having prominent complaints of dyspepsia (14), and the abdominal ultrasound examination revealed significantly dilated gastric antrum in patients with Type-1 diabetes. These findings were also supported by manometric studies. All these findings indicate the presence of slow gastric emptying in diabetic patients.

It has been realized that blood glucose levels have a critical role on gastric motility. Gastric emptying was slower in the hyperglycemic stage of the Type-1 DM patients with regard to glycemic stage (15). Glycemic control was obtained with oral antidiabetics and insulin in Type-2 DM and Type-1 DM patients, respectively, and the rate of gastric emptying remained unchanged. These findings conflict with decreased rate of gastric emptying in hyperglycemic patients (16). In the present study, there was no difference between the diabetic patients using insulin and those not using insulin in terms of symptoms and esophagogastroduodenoscopy findings.

Although certain researchers cannot find an association between autonomic nerve and gastric dysfunctions, few detected that autonomic dysfunction had a poor predictive impact on gastric emptying (17). Cardiovascular autonomic neuropathy is significantly and directly proportional to the gastric motor disorders.

In a study performed on Type 1 DM patients, abnormal gastroesophageal reflux activity was observed in 12 of 31 patients with cardiac autonomic dysfunction, and 2 of 19 patients with no cardiac autonomic dysfunction. This ratio was found to be higher in the diabetic patients comparing to the normal population (18). In the meta-analysis by Sun et al. in 2015, the incidence of gastroesophageal reflux disease was significantly higher in diabetic patients (19). In the present study, the incidence of hiatal hernia was higher in diabetic patients in comparison to the control group. Diabetic patients should be carefully examined in terms of gastroesophageal reflux and reflux symptoms due to the increased prevalence of hiatal hernia.

In the 5-year follow-up study, Marie-France Kong et al. reported higher duration of diabetic, autonomic neuropathy score and esophageal transit in deaths $(n=21)$ in comparison to the living patients; however, no difference was detected between the groups in terms of gastric emptying. In this study, they did not a find an association between gastroparesis and poor prognosis. In most of the patients, the presence of gastroparesis and upper GIS symptoms was found to be not associated with poor diagnosis (20).

Diabetic gastroparesis has a significant clinical importance as it leads to alterations in GIS symptoms, glycemic control and oral drug absorption (21). Alipour et al. found the prevalence of gastroparesis as $64 \%$ in diabetic patients (22). In the present study, there was no significant difference between patients with/without neuropathy in terms of endoscopic findings and GIS symptoms.

The symptoms are not characteristic in diabetic patients and even it is similar to those in non-diabetic individuals. The symptoms of diabetic gastropathy is mainly related to the upper GIS system. These symptoms involve diarrhea or constipation, abdominal pain or discomfort and heartburn according to their prevalence in diabetic patients. The symptoms of dyspepsia, nausea and vomiting shows similarities among diabetic and non-diabetic patients. Certain symptoms might vary in diabetic patients or they do not display any symptoms due to visceroreseptor malfunction. In certain studies, the number of symptoms in diabetic patients with slow gastric emptying were shown to be higher and divergent in comparison to the normal population (23). In our study, the GIS symptoms were similar in diabetic and control groups, and there was no significant difference between diabetic and nondiabetic patients in terms of the incidence of the symptoms.

Schvarcz et al. stated that the severity of upper GIS symptoms was higher in diabetic patients and patients with elevated levels of HbA1c had higher prevalence of symptoms (10). Khoshbaten et al. detected a correlation between the prevalence of GIS symptoms and glycemic control, duration of diabetes and diabetic complications (23). It was shown that patients with neuropathy had higher prevalence of symptoms. The severity of symptoms was found to directly proportional to the neuropathy, and the severity of symptoms had correlation with the glycemic control (24).

In the survey study of Peter Bytzer et al., the increased prevalence of GIS symptoms was found to 
be significantly associated with poor glycemic control level; however, the duration, type or treatment of diabetes were not related to the type of diabetes (7).

The increased prevalence of $H$. pylori was associated with higher exposure to the pathogens in diabetic patients when they were compared to the control group. The factors of delayed gastric emptying and gastric mucosal damage might cause bacterial overgrowth in the upper GI track in diabetic patients. Basal and stimulated acid secretion were reported as normal or decreased in diabetic patients (25).

Roussos et al. did not establish any significant difference between diabetic and non-diabetic patients in terms of $H$. pylori infection (26). They found higher incidence of gastric ulcer and lower incidence of peptic ulcer in diabetic patients comparing to the non-diabetics; however, these findings were not statistically significant. The prevalence of $H$. pylori infection in diabetic patients was serologically increased (27), and it has been shown in the histological study of Malecki et al. that $H$. pylori infection had a minor role in the upper GIS symptoms (28). Li et al. reported in their metaanalysis study that the prevalence of $H$. pylori infection in diabetic patients was significantly higher than the non-diabetic individuals and this difference was only associated with Type-2 DM (29).

In a study conducted in Ireland, the infection rate of H. pylori infection by histology of gastrointestinal mucosa was $74.4 \%$ in diabetic patients and $50 \%$ in the control group (ulcer $71 \%$, gastritis $43.5 \%$, simple dyspepsia 35\%) (27). Persico et al. determined a significant association between $H$. pylori infection and autonomic neuropathy $(84.7 \%)$, and the early prevalence of $H$. pylori infection in diabetic patients with dyspepsia was found to be higher than the nondiabetic individuals (30). Devrajani et al. showed that diabetic patients were more susceptible to the $H$. pylori infection (31).

\section{Conclusion}

In the present study, endoscopic findings were compared between diabetic patients with dyspepsia and non-diabetic individuals, and as the prevalence of gastric ulcer was significantly higher in diabetic group ( $\mathrm{p}=0.04)$, there was no statistically significant difference in terms of other endoscopic findings, including antral gastritis, pangastritis, duodenal ulcer, bulbitis, cardiac insufficiency, hiatal hernia and esophagitis. Despite of high prevalence of gastric ulcer in the diabetic group, there was no significant difference between GIS symptoms, diebetic complications and glycemic control among the patients having other endoscopic lesions.

Meantime, no significant difference was determined between diabetic patients with non-ulcer dyspepsia and diabetic patients with dyspepsia and duodenal ulcer in terms of GIS symptoms. The prevalence of hiatal hernia in the diabetic patients was higher than the control group. Diabetic patients should be carefully examined in terms of gastroesophageal reflux and reflux symptoms due to the increased prevalence of hiatal hernia.

\section{Acknowledgments, Funding: None}

Conflict of Interest: The authors declare no potential conflicts of interest with respect to the research, authorship, and/or publication of this article.

Author's Contributions: RIO, MK: Research concept and design; data collecting, biochemical analysis and interpretation of data. All authors approved the final version of the manuscript,

Ethical issues: All Authors declare that Originality of research/article etc... and ethical approval of research, and responsibilities of research against local ethics commission are under the Authors responsibilities. The study was conducted due to defined rules by the Local Ethics Commission guidelines and audits.

\section{References}

1. Harrison İç Hastalıkları Prensipleri, cilt 2, 2004, Nobel Kitabevleri, 2109-2137 (Çeviri Editörü: Prof.Dr.Yahya Sağlıker,2004)

2. Talley NJ, Stanghellini V, Heading RC, Koch KL, Malagelada JR, Tytgat GN. Functional gastroduodenal disorders. Gut 1999;45 Suppl 2:1137-1142.

3. Kassander P. Asymptomatic gastric retention in diabetics (gastroparesis diabeticorum). Ann Intern Med 1958;48(4):797-812.

4. Takeuchi K, Ueshima K, Ohuchi T, Okabe S. Induction of gastric lesions and hypoglycemic response by food deprivation in streptozotocin-diabetic rats. Dig Dis Sci 1994;39(3):626-634.

5. Parkman HP, Hasler WL, Fisher RS. American Gastroenterological Association. American Gastroenterological Association technical review on the diagnosis and treatment of gastroparesis. Gastroenterology 2004;127(5):1592-1622.

6. Calvet $\mathrm{X}$, Bustamante $\mathrm{E}$, Montserrat $\mathrm{A}$, Roqué $\mathrm{M}$, Campo R, Gené $E$, et al. Validation of phone interview for follow-up in clinical trials on dyspepsia: Evalution of the Glasgow Dyspepsia Severity Score and a Likert-scale symptoms test. Eur J Gastroenterol Hepatol 2000; 12: 949-953.

7. Bytzer $\mathrm{P}$, Talley NJ, Leemon M, Young LJ, Jones MP, Horowitz $M$. Prevalence of gastrointestinal symptoms associated with diabetes mellitus: a population-based survey of 15,000 adults. Arch Intern Med 2001;161(16):1989-1996.

8. Koch CA, Uwaifo GI. Are gastrointestinal symptoms related to diabetes mellitus and glycemic control? Eur J Gastroenterol Hepatol 2008;20(9):822-825. 
9. Bharucha AE, Batey-Schaefer B, Cleary PA, Murray JA, Cowie $C$, Lorenzi $\mathrm{G}$, et al. Delayed gastric emptying is associated with early and long-term hyperglycemia in type 1 diabetes mellitus. Gastroenterology 2015;149:330-339.

10. Schvarcz $E$, Palmer $M$, Ingberg $C M$, Aman J, Berne $C$. Increased prevalence of upper gastrointestinal symptoms in long-term type 1 diabetes mellitus. Diabet Med 1996;13(5):478-481.

11. Eslick GD. Gastrointestinal symptoms and obesity: a metaanalysis. Obes Rev 2012;13(5):469-479.

12. Jebbink HJ, Bravenboer B, Akkermans $L M$, vanBergeHenegouwen GP, Smout AJ. Relationships between dyspeptic symptoms and gastrointestinal motility in patients with type 1 (insulin-dependent) diabetes mellitus. Diabetologia 1993;36(10):948- 954.

13. Malagelada JR, Rees WD, Mazzotta L, Go VL. Gastric motor abnormalities in diabetic and postvagotomy gastroparesis: effect of metoclopramide and bethanechol. Gastroenterology 1980;78(2):286-293.

13. Stacher $G$, Lenglinger J, Bergmann $H$, Schneider $C$, Brannath $W$, Festa $A$, et al. Impaired gastric emptying and altered intragastric meal distribution in diabetes mellitus related to autonomic neuropathy? Dig Dis Sci 2003;48(6):1027-1034.

14. Samsom $M$, Akkermans $L M$, Jebbink $R J$, van Isselt $H$, vanBerge-Henegouwen GP, Smout AJ. Gastrointestinal motor mechanisms in hyperglycaemia induced delayed gastric emptying in type I diabetes mellitus. Gut 1997;40(5):641-646.

15. Holzapfel A, Festa A, Stacher-Janotta G, Bergmann H, Shnawa N, Brannath W, et al. Gastric emptying in Type II (non-insulindependent) diabetes mellitus before and after therapy readjustment: no influence of actual blood glucose concentration. Diabetologia 1999;42(12):1410-1412.

16. Annese V, Bassotti G, Caruso N, De Cosmo S, Gabbrielli A, Modoni $S$, et al. Gastrointestinal motor dysfunction, symptoms, and neuropathy in noninsulin-dependent (type 2) diabetes mellitus. J Clin Gastroenterol 1999;29(2):171-177.

17. Lluch I, Ascaso JF, Mora F, Minguez M, Pena A, Hernandez A et al. Gastroesophageal reflux in diabetes mellitus. Am J Gastroenterol 1999;94(4):919- 924.

18. Sun XM, Tan JC, Zhu Y, Lin L. Association between diabetes mellitus and gastroesophageal reflux disease: A metaanalysis. World J Gastroenterol 2015;21(10):3085-3092.

19. Kong MF, Horowitz M, Jones KL, Wishart JM, Harding PE. Natural history of diabetic gastroparesis. Diabetes Care 1999;22(3):503-507.
20. Horowitz $M$, Fraser R. Disordered gastric motor function in diabetes mellitus. Diabetologia 1994;37(6):543-551.

21. Alipour Z, Khatib F, Tabib SM, Javadi H, Jafari E, Aghaghazvini $L$, et al. Assessment of the Prevalence of Diabetic Gastroparesis and Validation of Gastric Emptying Scintigraphy for Diagnosis. Mol Imaging Radionucl Ther 2017;26(1):17-23.

22. Khoshbaten $M$, Madad L, Baladast $M$, Mohammadi $M$, Aliasgarzadeh A. Gastrointestinal signs and symptoms among persons with diabetes mellitus. Gastroenterol Hepatol Bed Bench 2011;4(4):219-223.

23. Spangeus A, El-Salhy M, Suhr O, Eriksson J, Lithner F. Prevalence of gastrointestinal symptoms in young and middle-aged diabetic patients. Scand J Gastroenterol 1999;34(12):1196-1202.

24. Feldman M, Schiller LR. Disorders of gastrointestinal motility associated with diabetes mellitus. Ann Intern Med 1983;98(3):378-384.

25. Anastasios R, Goritsas C, Papamihail C, Trigidou R, Garzonis P, Ferti A. Helicobacter pylori infection in diabetic patients: prevalence and endoscopic findings. Eur J Intern Med 2002;13(6):376

26. Gentile S, Turco S, Oliviero B, Torella R. The role of autonomic neuropathy as a risk factor of Helicobacter pylori infection in dyspeptic patients with type 2 diabetes mellitus. Diabetes Res Clin Pract 1998;42(1):41-48.

27. Malecki M, Bien Al, Galicka-Latala D, Stachura J, Sieradzki J. The prevalance of Helicobacter pylori infection and types of gastritis in diabetic patients. The Krakow study. Exp Clin Endocrinol Diabetes 1996;104:365-369.

28. Li JZ, Li JY, Wu TF, Xu JH, Huang CZ, Cheng D, et al. Helicobacter pylori Infection is Associated with Type 2 Diabetes, Not Type 1 Diabetes: An Updated Meta-Analysis. Gastroenterol Res Pract 2017;2017:5715403.

29. Persico M, Suozzo R, De Seta M, Montella F, Torella R, Gentile S. Non-ulcer dyspepsia and Helicobacter pylori in type 2 diabetic patients: association with autonomic neuropathy. Diabetes Res Clin Pract 1996;31(1-3):87-92.

31. Devrajani BR, Shah SZ, Soomro AA, Devrajani T. Type 2 diabetes mellitus: a risk factor for Helicobacter pylori infection: a hospital based case-control study. Int J Diabetes Dev Ctries 2010;30(1):22-26.

Copyright (C) 2018 The Author(s); This is an open-access article distributed under the terms of the Creative Commons Attribution License (http://creativecommons.org/licenses/by/4.0), which permits unrestricted use, distribution, and reproduction in any medium, provided the original work is properly cited. All Rights reserved by international journal of Medical Science and Discovery. 